\title{
Effects of carrying school bags on cervical and shoulder posture in static and dynamic conditions in adolescent students
}

\author{
${ }^{1}$ Bachelor of Physiotherapy, Sancheti Institute College of Physiotherapy, Pune, India \\ ${ }^{2}$ Masters in Neurophysiotherapy, Assistant Professor, Sancheti College of Physiotherapy, 11/12, Thube Park, Shivajinagar, Pune \\ 411005, Maharashtra, India, E-mail: drdineshchavhan@gmail.com \\ ${ }_{3}^{3}$ MS Orthopaedics, Research Officer, Sancheti Institute for Orthopaedics and Rehabilitation, Pune, India \\ ${ }^{4}$ MS Orthopaedics, Chairman, Sancheti Institute for Orthopaedics and Rehabilitation, Pune, India
}

\begin{abstract}
:
Background: Neck and Back Pain in Students is closely related to the school bags that they carry. There is a dearth of literature in terms of postural changes due to school bags in adolescents, especially those discussing postural changes in static and dynamic loading conditions.

Objective: To assess the effects of weight, position, and time of school bag carriage in static and dynamic conditions on cervical and shoulder posture in adolescent students.

Subjects: Seventy adolescents (35 Females, 35 Males) between 10 and 15 years of age.

Methods: Craniohorizontal Angle, Craniovertebral Angle, Sagittal Shoulder Posture, Anterior Head Alignment were assessed in 7 different conditions using Photographic Method and MB Ruler.

Results and Conclusion: Significant changes in Sagittal Shoulder Posture and Craniohorizontal Angle were found with unilateral school bag carriage as compared to minimal significant postural changes with bilateral carriage. Maximal significant postural changes, in terms of all outcome measures were noted during loaded dynamic activity. Craniovertebral Angle kept significantly reducing with time. Immediate assessments taken with a school bag weighing $13.5 \%$ of the body weight showed a significant decrement in the Craniohorizontal Angle. Even a bag weighing less than $10 \%$ of the body weight proved to bring about biomechanical changes, when assessments were taken during the activities that a child has to perform with a school bag (Post Standing, Post Walking, and During Walking).
\end{abstract}

Keywords: adolescents, cervical posture, school bag, shoulder posture, static and dynamic loading DOI: $10.1515 /$ ijamh-2019-0073

Received: March 26, 2019; Accepted: May 19, 2019

\section{Introduction}

Adolescents account for more than 1.2 billion of the world's population [1]. In India, adolescents comprise $19.6 \%$ of the population [2]. The nation's future lies in the hands of these very adolescents who will grow up to be the driving force of the economy, and thus, the promotion and protection of their health becomes a priority.

Adolescence encompasses age the groups from 10 to 19 years [1]. It is during these years of accelerated soft tissue and skeletal structure growth, that they are most prone to acquire musculoskeletal disorders. There are a number of psychosocial and physical factors which govern the presence of back pain in school children [3]. One such physical factor is the postural changes brought about by carrying school bags [4]. Complaints of back pain during childhood or adolescence will also influence musculoskeletal health later in life, as it is predictor of back ache in adulthood [5], [6]. Thus, assessment of the effect of carrying school bags on posture becomes extremely crucial if these problems are to be dealt with efficiently.

Neck pain and back pain are closely related to the backpacks that students carry to school [7], [8], [9]. As per previous research work, it has been established that backpack load placement has an effect on posture and spinal curvature in prepubescent school-going children [10]. However, there is a dearth of literature with regards to adolescent school children in whom there is a significant requirement of such research work and varied responses expected. Amongst such studies, is a study done by Pascoe et al., which showed that carrying 
a backpack unilaterally leads to an increase in forward head position and elevation of the shoulder of the same side [11]. However, no information about the position of the head on the neck and the position of the neck on the thorax was conveyed through this, which becomes an important piece of information because, an altered alignment of the cervical spine can lead to undue strain on the skeletal and soft tissue structures leading to an imbalanced muscle performance. This will ultimately cause cervical pain, and pain in the shoulder and upper thoracic regions [12]. This limitation was overcome by another study done by Chansirinukor et al. [13], though, due to the limitation of a small sample size, it could only show a few significant changes. Also, the effect of time for which the bag was carried in static and dynamic loading conditions was not studied. A school-going child is exposed to a variety of static and dynamic conditions to do with the school bag. It is therefore imperative to study the biomechanical changes in all these conditions in order to draw an accurate inference when assessing the effects of carrying a school bag on posture as they will tend to influence the results. Hong et al. demonstrated the changes in spinal posture in children during stair climbing [14]. But, there is a lack of literature in terms of changes in cervical and shoulder posture with carrying a school bag during level ground walking, which has also been chosen as one of the conditions in the present study. Dianat et al. concluded that parental awareness negatively correlated to prevalence of upper back pain and shoulder pain in students. Furthermore, they also showed that awareness of specific variables like weight limit and correct method of carrying was generally low [15]. Results from this study, could be used to provide objective data to educate parents about the possible postural changes occurring due to carrying school bags.

\section{Materials and methodology}

\section{Sample population}

As per the sample size calculated, 70 school-going subjects between the ages of 10 and 15 years [mean: 12.19; standard deviation (SD): 1.72] were recruited for the study. These subjects were included on the basis of voluntary enrolment, with a final count of 35 females and 35 males. Subjects with a history of trauma to the cervical, thoracic or lumbar spine, or scapula and glenohumeral joint; history of spinal surgery; congenital or acquired disorders of the spine; and those with limb length discrepancy were excluded from the study. The research study was approved by the Institutional Review Board. An assent was taken from all the participating subjects, and a written consent was taken from their parents/guardians.

\section{Assessment}

Prior to the assessments, the demographic data of each subject was collected which included name, age (in years), gender, height (in $\mathrm{cm}$ ), weight of the subject (in $\mathrm{kg}$ ), weight of the school bag (in $\mathrm{kg}$ ), and weight of the school bag to weight of the subject (in percentage) (Table 1). The photographic method was used to assess the posture of each subject, for which adhesive markers were applied to anatomical landmarks after properly exposing each landmark. Landmarks of interest were external canthus of right eye, right tragus, inferior margins of both ears, mid-point of head of humerus, and spinous process of $\mathrm{C} 7$ vertebrae, wherein the right side was kept constant for uniformity. The following four angles were used as outcome measures.

Table 1: Demographics of the subjects ( $n=70)$; females: 35; males: 35.

\begin{tabular}{lrrr} 
Variables & Mean (SD) & Minimum & Maximum \\
\hline Age, years & $12.19(1.72)$ & 10.0 & 15.0 \\
Height, cm & $153.52(10.77)$ & 131.0 & 176.0 \\
Weight of subject, $\mathrm{kg}$ & $45.36(13.73)$ & 21.0 & 96.0 \\
Weight of school bag, kg & $4.15(1.43)$ & 1.5 & 9.5 \\
School bag weight/body weight, \% & $9.8(4.2)$ & 4.0 & 20.0 \\
\hline
\end{tabular}

$\mathrm{SD}$, standard deviation.

In the lateral view (sagittal plane):

1. Craniohorizontal angle: The angle formed between a horizontal line passing through the tragus of the ear and another line joining the tragus of the ear to the external canthus of the eye, was measured. It gives an 
idea about the position of head on the neck or in other words, the position of the upper cervical spine [16] (Figure 1).

2. Craniovertebral angle: The angle formed between a horizontal line passing through the $C 7$ spinous process and another line joining the $\mathrm{C} 7$ spinous process and the tragus of the ear, was measured. This gives an idea about the position of the neck on the upper trunk or in other words, the position of the lower cervical spine [17] (Figure 2).

3. Sagittal shoulder posture: The angle formed between a horizontal line through the C7 spinous process and another line joining the $\mathrm{C} 7$ spinous process to the mid-point of the head of humerus, was measured. This gives an indication about a forward shoulder position [16] (Figure 3).

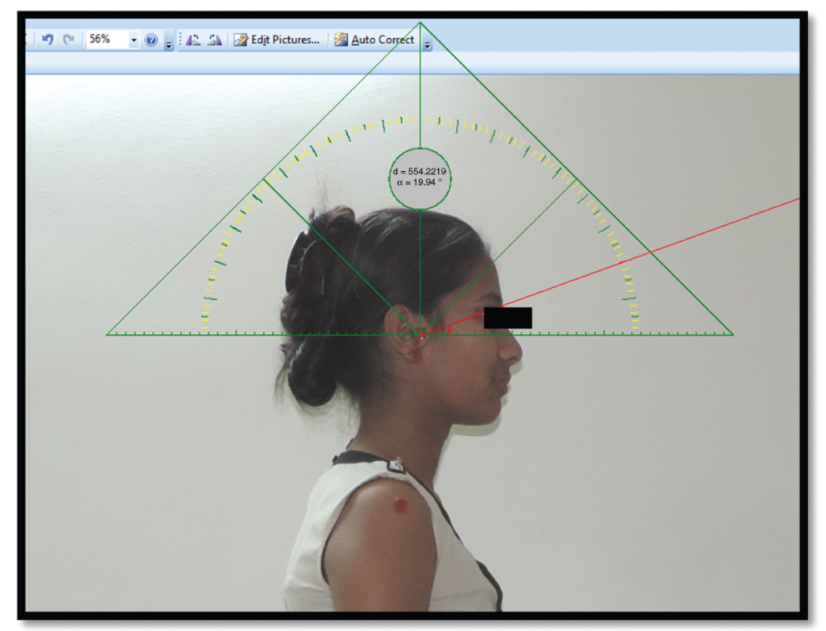

Figure 1: Craniohorizontal angle (unloaded).

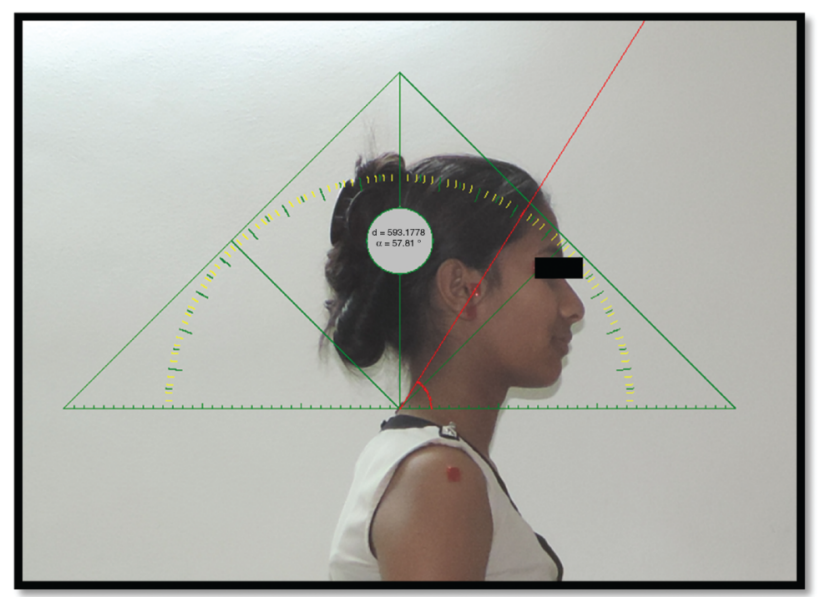

Figure 2: Craniovertebral angle (unloaded).

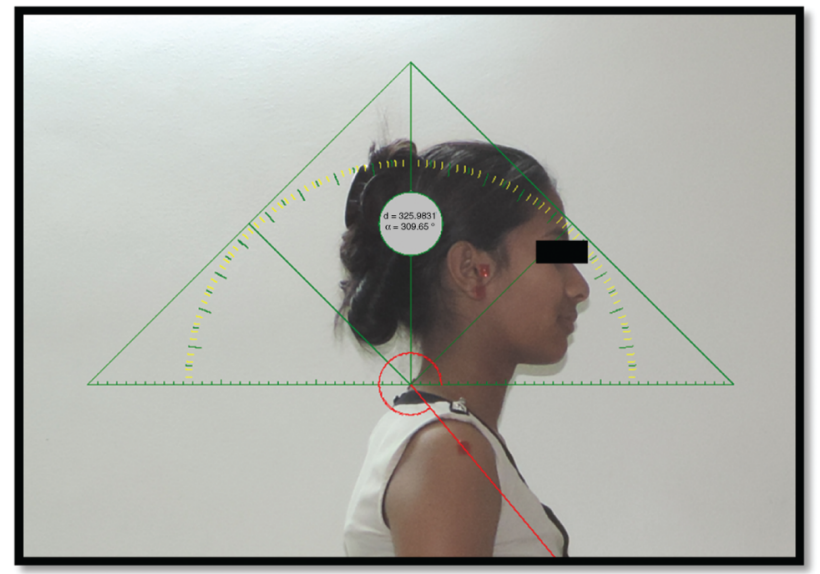


Figure 3: Sagittal shoulder posture (unloaded).

In the anterior view (frontal plane):

1. Anterior head alignment: The angle formed between a line parallel to the floor and another line joining the inferior margins of both the ears, was measured. This angle gives an indication about the tilt of the head in the coronal plane. When the eyes are level, this angle is zero. For the purpose of this study, a positive angle was considered when the left earlobe was higher than the right earlobe (right lateral neck flexion), and a negative angle was considered when the right earlobe was higher than the left earlobe (left lateral neck flexion) [16] (Figure 4).

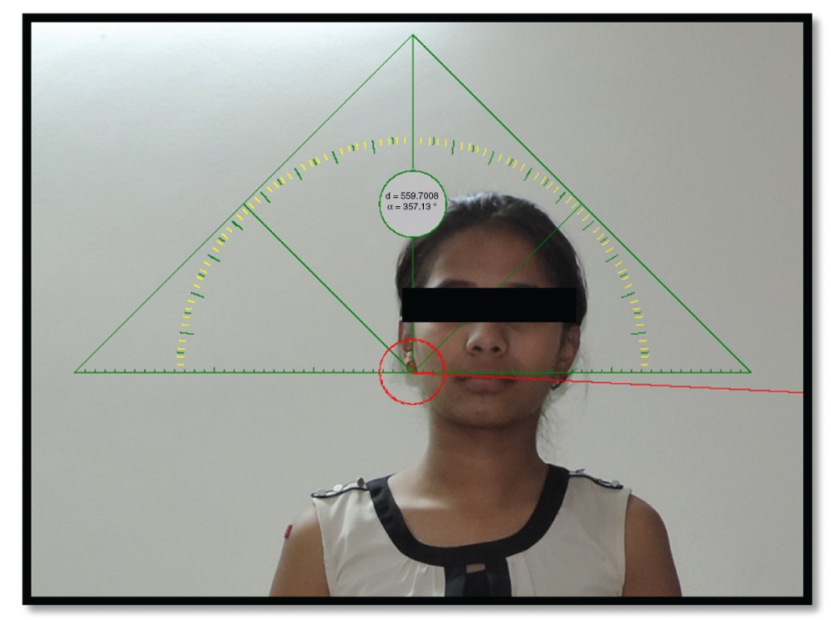

Figure 4: Anterior head alignment (unloaded).

\section{Procedure}

Parallel lines perpendicular to the frontal plane were drawn $2 \mathrm{~cm}$ apart, between which the lateral malleoli were placed. Each subject stood barefooted, bearing equal weight on both the legs, in a relaxed position, and with arms by the side of the body, while looking straight ahead. The tripod stand with the camera atop it was placed in two different positions. First, $1.5 \mathrm{~cm}$ to the right side of the subject, and then $1.5 \mathrm{~cm}$ in front of the subject, at a height of $115 \mathrm{~cm}$ each time. As per the repeated measures study design, each subject had 12 photographs taken, six from the anterior aspect and six from the right lateral aspect, along with a 15-s video which was taken during initial walking, and was later converted into images to assess the changes in the outcome measures during loaded dynamic activity. In total the postural changes were assessed in the following seven situations:

1. Without a school bag (unloaded)

2. With a school bag (over both shoulders)

3. Carrying the school bag unilaterally (over right shoulder)

4. After carrying the school bag and standing for $5 \mathrm{~min}$ (post standing for $5 \mathrm{~min}$ )

5. After carrying the school bag and walking for $5 \mathrm{~min}$ (post walking for $5 \mathrm{~min}$ )

6. Walking with the school bag (during walking)

7. Carrying a school bag weighing $13.5 \%$ of their body weight. (Studies have shown that a backpack weighing $15 \%$ of the body weight brings about significant postural changes in a student's posture [13]. Alternatively, a backpack weighing 10\% does not bring about any significant postural changes [18]. A school bag weighing $13.5 \%$ of the subject's body weight was thus used in this research, to study the postural changes that occur at the midpoint of both these extreme conditions).

Each photograph was then assessed for the four outcome measures using the MB Ruler software [19]. 


\section{Results}

The data was analysed using SPSS software, wherein repeated measures analysis of variance (ANOVA) was used as the statistical test, with an alpha value of less than $0.05(\alpha<0.05)$ being considered as significant.

Table 2 shows the mean and standard deviation values for craniohorizontal angle, craniovertebral angle, sagittal shoulder posture and anterior head alignment in all the seven chosen conditions.

Table 2: Mean and SD values (degrees) from postural assessment.

\begin{tabular}{lrrrr}
\hline Conditions/factors & $\begin{array}{r}\text { Craniohorizontal } \\
\text { angle } \\
\text { Mean (SD) }\end{array}$ & $\begin{array}{r}\text { Craniovertebral } \\
\text { angle } \\
\text { Mean (SD) }\end{array}$ & $\begin{array}{r}\text { Sagittal shoulder } \\
\text { posture } \\
\text { Mean (SD) }\end{array}$ & $\begin{array}{r}\text { Anterior head } \\
\text { alignment } \\
\text { Mean (SD) }\end{array}$ \\
\hline Unloaded & $16.04(7.17)$ & $50.13(7.11)$ & $54.28(11.43)$ & $0.73(3.02)$ \\
Over both shoulders & $16.90(7.91)$ & $46.71(6.60)$ & $54.43(13.62)$ & $0.71(3.25)$ \\
Over right shoulder & $14.64(7.47)$ & $46.96(7.73)$ & $61.42(22.40)$ & $-0.05(4.31)$ \\
Post standing for 5 min & $18.18(8.03)$ & $45.77(6.30)$ & $54.43(13.46)$ & $1.27(2.90)$ \\
Post walking for 5 min & $18.02(8.13)$ & $45.65(6.59)$ & $53.82(11.62)$ & $1.00(2.92)$ \\
During walking & $16.57(10.57)$ & $49.00(8.05)$ & $64.90(16.61)$ & $0.00(0.00)$ \\
13.5\% of body weight & $15.59(9.33)$ & $39.48(14.77)$ & $49.10(21.50)$ & $0.80(2.76)$ \\
\hline
\end{tabular}

$\mathrm{SD}$, standard deviation.

Table 3 depicts the level of significance of the planned contrasts for each outcome measure for a comparison drawn between each loaded condition with the unloaded condition.

Table 3: $\mathrm{p}$-Values of the planned contrasts for craniohorizontal angle, craniovertebral angle, sagittal shoulder posture and anterior head alignment for each loaded condition compared with the unloaded condition.

\begin{tabular}{|c|c|c|c|c|}
\hline Conditions/factors & $\begin{array}{r}\text { Craniohorizontal } \\
\text { angle } \\
\text { Mean (SD) }\end{array}$ & $\begin{array}{r}\text { Craniovertebral } \\
\text { angle } \\
\text { Mean (SD) }\end{array}$ & $\begin{array}{r}\text { Sagittal shoulder } \\
\text { posture } \\
\text { Mean (SD) }\end{array}$ & $\begin{array}{r}\text { Anterior head } \\
\text { alignment } \\
\text { Mean (SD) }\end{array}$ \\
\hline Over both shoulders & 0.725 & $0.000^{\mathrm{a}}$ & 0.803 & 0.903 \\
\hline Over right shoulder ${ }^{b}$ & $0.045^{\mathrm{a}}$ & 0.179 & $0.006^{\mathrm{a}}$ & 0.928 \\
\hline Post standing for $5 \mathrm{~min}^{\mathrm{b}}$ & 0.059 & $0.000^{\mathrm{a}}$ & $0.032^{\mathrm{a}}$ & 0.676 \\
\hline Post walking for $5 \mathrm{~min}^{\mathrm{b}}$ & 0.818 & $0.000^{\mathrm{a}}$ & $0.000^{\mathrm{a}}$ & $0.005^{\mathrm{a}}$ \\
\hline During walking b & $0.003^{\mathrm{a}}$ & $0.000^{\mathrm{a}}$ & $0.000^{\mathrm{a}}$ & - \\
\hline $13.5 \%$ of body weight & $0.006^{\mathrm{a}}$ & 0.469 & 0.522 & 0.105 \\
\hline
\end{tabular}

aSignificant values. ${ }^{b}$ Carrying own school bag weight.

\section{Discussion}

\section{Effects of weight of carrying a school bag}

The results of this study indicate that minimum significant postural changes were found when a comparison was drawn between the baseline condition (unloaded) and bilaterally equally loaded condition (over both shoulders) (Table 3). This is in line with the study done by Mossad et al. in 2014 [20], which showed that carrying a school bag bilaterally elicited less and more symmetric electromyography (EMG) activity as compared to a unilateral load.

However, the reduction in the craniovertebral angle was found to be significant in the above situation and confirms the findings of a similar study done by Chansirinukor et al. in 2001 [13]. Kim et al. 2018 showed that reduced a craniovertebral angle causes flexion at the lower cervical spine and compensatory extension at the upper cervical spine to accommodate the horizontal gaze. As a result, the centre of gravity (at the head) shifts ahead, increasing the moment arm and taking it away from the load bearing axis. This in turn increases the stress on the extensor muscles and surrounding connective tissues of the posterior craniocervical region, which causes an imbalance in the neck and leads to myofascial pain [21]. This was proven objectively by Khayatzadeh et al. in 
2017, wherein they showed that the occipital extensors and cervical flexors shortened, and occipital flexors and cervical extensors lengthened. This same study also proved another possible cause of craniocervical pain by showing that the shortened rectus capitis posterior minor in turn exerted continuous tension on the myodural bridges leading to pain [22].

Minimal significant postural changes were found when a subject was asked to carry a school bag weighing $13.5 \%$ of his / her body weight, which included a reduction of the craniohorizontal angle (Table 2). However, this assessment was taken immediately after the subject was loaded bilaterally, and not in the other conditions. As the results clearly indicate, more significant changes in all four angles are brought about as time of load carriage increases, and thus, the effect of specific loading could be studied and discussed better if assessed accordingly.

\section{Effects of position of carrying a school bag on the vertebral spine}

The results of this study show that carrying a school bag on one shoulder (right shoulder taken to maintain uniformity) leads to significant retropositioning of the shoulder and a significant decrease in the craniohorizontal angle (Table 2). This is in line with the findings of the studies done by Chansirinukor et al. [13] and Negrini et al. [23] which showed an increase in the sagittal shoulder posture and a reduction in craniohorizontal angle with asymmetric loading.

When the schoolbag is carried unilaterally on one shoulder, the weight of the bag is more lateral, and thus in an attempt to maintain the centre of gravity (COG) within the base of support (BOS), and to ensure that the bag remains stabilised on the shoulder, the subject tilts the trunk away from the schoolbag and retropositions the shoulder [24].

Wonh-Wee et al., showed that carrying a bag unilaterally led to an increased activity in the upper trapezius muscles of the ipsilateral side, which would in turn lead to irritation of the occipital nerve giving rise to tension headaches, shoulder pain and cervical spine pain [25].

\section{Effects of time}

When the subjects were asked to carry their own school bag and stand in one place for 5 min, post the static activity, the postural changes were found to be significant in terms of the decrement of the craniovertebral angle and increment of sagittal shoulder posture, which coincide with the result of a similar study [26].

This reduction in the craniovertebral angle is more than that which was measured when a comparison between unloaded (baseline) and bilaterally equally loaded situation was drawn, further proving that the longer the school bag is carried by the subject, the more are the postural changes brought about, which indicates that the time for which the school bag is carried does have a significant effect on a student's posture.

The results also show significant increase in sagittal shoulder posture post $5 \mathrm{~min}$ of static activity. However, the level of significance is much less as compared to that of the craniovertebral angle, which brings us to a valid point which was put forth by Chansirinukor et al. in their study, where they showed that a decrease in the craniovertebral angle could possibly sometimes lead to a false increase in sagittal shoulder posture. This is because, with an increase in craniovertebral angle, the C7 spinous process moves anteriorly, and the closer C7 and the mid-point of head of humerus are, the larger is the sagittal shoulder posture calculated [13]. And thus, a three-dimensional (3D) analysis of the anatomical landmarks and their relationship is required to conclusively discuss about these changes.

The assessments made, after the subject carried out a dynamic activity of walking for 5 min showed significant changes in the craniovertebral angle, sagittal shoulder posture, and anterior head alignment.

The anterior head alignment shows significant changes only when the assessment is taken post 5 min of walking, and in no other condition. This change in the angle could be attributed purely due to fatigue and reduced capacity of the muscles on one side, to maintain the neck in a stable position in the loaded condition. A study showed that carrying a bag bilaterally led to increased EMG activity in bilateral trapezius muscles, with EMG activity being higher on the right/dominant side as compared to the left side [20] which could be another reason for the increase in the anterior head alignment. However, further studies are required to confirm these particular findings.

The craniovertebral angle reduces further from the baseline value after 5 min of walking, which in turn could be a potential source for neck and upper back pain problems as already discussed earlier. The sagittal shoulder posture shows a reduction when compared to the baseline condition which again could be attributed to fatigue of the muscles to maintain the posture over a period of time, and requires further study. 


\section{Effects of school bag carriage with dynamic activity}

The results from this study clearly indicate that maximal significant postural changes were noted when a subject was asked to walk at his/her own pace while carrying their own school bag, which included an increase in craniovertebral angle, a reduction in craniohorizontal angle and an increase in sagittal shoulder posture.

This is in line with a study done by Attwells et al. which showed similar results. The 2007 study was done on soldiers to see the effect of the heavy loads that they carry while walking, on their posture, movement and gait, and showed that trunk forward lean increased with a simultaneous decrease in craniovertebral angle. In order to propel the body forward, a subject has to shift the COG anteriorly by leaning the trunk forward, to move it out of the BOS and hence bring about a stepping response. When a subject is walking while carrying a load, more trunk forward lean will be required to not only shift the COG, but also counterbalance the posteriorly placed school bag weight. This is further facilitated by a reduction in the craniovertebral angle which shifts the head forward. Together the craniovertebral angle and trunk forward lean act as a single unit providing dynamic balance to stabilize the body during walking [27]. This was accompanied with a simultaneous increase in the craniohorizontal angle, yet again in an attempt to maintain the horizontal gaze. However, perusal of the results shows that this increase in the craniohorizontal angle is less as compared to the increase with immediate static loading. A possible explanation for this could be that during walking a person tries to look down-ahead instead of straight-ahead to watch out for obstacles on the ground. During the assessment, subjects were not asked to look straight ahead while walking to avoid obtaining a bias during results, and thus said results for the craniohorizontal angle were obtained.

\section{Conclusion}

Carrying a school bag was found to significantly influence cervical and shoulder posture when measured in terms of the craniohorizontal angle, the craniovertebral angle, sagittal shoulder posture and anterior head alignment, in all the chosen conditions. Minimal significant postural changes were found when a school bag was carried bilaterally, and a significant increase in the sagittal shoulder posture and significant decrease in the craniohorizontal angle was found with unilateral school bag carriage, which concluded that bilateral school bag carriage is biomechanically better than unilateral carriage. The assessments taken after 5 min of standing, after 5 min of walking, and during walking showed significant postural changes in all outcome measures, which proved that even a bag weight of less than $10 \%$ of the body weight (which was the mean for percentage bag weight of body weight) brings about biomechanical changes, if assessments are taken during the activities that a child has to perform with a school bag, the craniovertebral angle reduced further, post $5 \mathrm{~min}$ of standing with the school bag. Maximal significant postural changes were observed, in terms of all outcome measures, during dynamic activity of walking while carrying the school bag. Immediate assessments taken after loading a subject with a school bag weighing $13.5 \%$ of their body weight showed a significant decrement in the craniohorizontal angle.

\section{Limitations and future scope of study}

1. Each subject was asked to walk at their own pace during the dynamic activity assessment, and speed was not kept uniform. A particular speed limit can be decided, and repeat assessments can be performed at different speeds to study the effect of speed on cervical and shoulder posture in a loaded scenario.

2. Physiological and biomechanical variations between boys and girls were not taken into consideration.

\section{Acknowledgements}

I would like to take this opportunity to extend my sincere gratitude to Dr. Dhara Kapoor (PT) for her constant support and guidance at each and every step. I would like to thank Dr. Rachana Dabadghav (Research Coordinator at Sancheti Institute College of Physiotherapy). I would like to thank the honourable Institutional Review Board for permitting me to undertake this study. And most importantly, a wholesome thanks you to all the adolescents and their parents for agreeing to be a part of this study. 


\section{References}

[1] [Internet]. 2019. p. 6. Available from: https://www.unicef.org/publications/files/Progress_for_Children_-_No._10_EN_04232012.pdf.

[2] Census of India Website: Office of the Registrar General \& Census Commissioner, India [Internet]. Censusindia.gov.in. 2019 [cited 2019 May 2]. Available from: http://www.censusindia.gov.in/2011census/population_enumeration.html.

[3] Oka G, Ranade A, Kulkarni A. Back pain and school bag weight - a study on Indian children and review of literature. ] Pediatr Orthop B. 2019;28(4):397-404.

[4] Korovessis P, Koureas G, Zacharatos S, Papazisis Z. Backpacks, back pain, sagittal spinal curves and trunk alignment in adolescents. Spine. 2005;30(2):247-55.

[5] Jones CT, MacFarlane G]. Epidemiology of low back pain in children and adolescents. Arch Dis Child. 2005;90(3):312-6.

[6] Brattberg C. Do pain problems in young school children persist into early adulthood? A 13-year follow-up. Eur] Pain. 2004;8(3):187-99.

[7] Sheir-Neiss G, Kruse R, Rahman T, Jacobson L, Pelli ]. The association of backpack use and back pain in adolescents. Spine. 2003;28(9):922-30.

[8] lyer S. An ergonomic study of chronic musculoskeletal pain in schoolchildren. Indian ] Pediatr. 2001;68(10):937-41.

[9] Negrini S, Carabalona R, Pinochi G, Malengo R, Sibilla P. Backpack and back pain in school children: is there a direct relationship?] Bone Joint Surg Am. 1998;80(3S):247.

[10] Brackley HM, Stevenson JM, Selinger ]C. Effect of backpack load placement on posture and spinal curvature in prepubescent children Work. 2009;32(3):351-60.

[11] Pascoe DD, Pascoe DE, Wang YT, Shim DM, Kim CK. Influence of carrying book bags on gait cycle and posture of youths. Ergonomics. 1997;40(6):631-40.

[12] Mannheimer]S, Rosenthal RM. Acute and chronic postural abnormalities as related to craniofacial pain and temporomandibular disorders. Dent Clin North Am. 1991;35(1):185-208.

[13] Chansirinukor W, Wilson D, Grimmer K, Dansie B. Effects of backpacks on students: measurement of cervical and shoulder posture. Aust J Physiother. 2001;47:110-6.

[14] Hong Y, Fong D, Li ]. The effect of school bag design and load on spinal posture during stair use by children. Ergonomics. 2011;54(12):1207-13.

[15] Dianat I, Karimi M. Association of parental awareness of using schoolbags with musculoskeletal symptoms and carrying habits of schoolchildren. J School Nurs. 2013;30(6):440-7.

[16] Raine S, Twomey L. Posture of the head, shoulders and thoracic spine in comfortable erect standing. Aust ] Physiother. 1994;40(1):25-32.

[17] Wickens ]S, Kiphuth OW. Body mechanics analysis of Yale University freshmen. Research Quarterly. Am Phys Educ Assoc. 1937;8(4):38-48.

[18] Voll H, Klimt F. Translated by Theodoridis D. Strain in Children caused by carrying Schoolbags (from Die Beanspruchung des kindes durch die schultasche). Offentliche Cesundheitswesen. 1977;39(7):369-78.

[19] Hazar Z, Karabicak CO, Tiftikci U. Reliability of photographic posture analysis of adolescents. ] Phys Ther Sci. 2015;27(10):3123-6.

[20] Dalia M, Nabawy Heba E-S, Wadida E-S. Influence of load carriage on electromyographic activities of upper fibres of trapezius in school students during walking. Med ] Cairo Univ. 2014;82(2):61-65.

[21] Kim DH, Kim C], Son SM. Neck pain in adults with forward head posture: effects of craniovertebral angle and cervical range of motion. Osong Public Health Res Perspect. 2018;9(6):309.

[22] Khayatzadeh S, Kalmanson OA, Schuit D, Havey RM, Voronov LI, Chanayem A], et al. Cervical spine muscle-tendon unit length differences between neutral and forward head postures: biomechanical study using human cadaveric specimens. Phys Ther. 2017;97(7):75666.

[23] Negrini S, Negrini A. Postural effects of symmetrical and asymmetrical loads on the spines of schoolchildren. Scoliosis. 2007;2(1):8.

[24] Samuel W. Biomechanical applications to joint structure and function. In: Pamela L, Cynthia N, editors. Joint structure and function, a comprehensive analysis. 5th ed. India: Jaypee Brothers; 2011:16-7.

[25] Wonh-wee L. Effects of same-sided and cross-body load carrying on the activity of the upper trapezius and erector spinae muscles. ] Musculoskel Sci Technol. 2017;1(1):2-6.

[26] Mathur H, Desai A, Khan SA. To determine the efficacy of addition of horizontal waist strap to the traditional double shoulder strap school backpack loading on cervical and shoulder posture in Indian school going children. Int ] Phys Med Rehabil. 2017;5(434):2.

[27] Attwells RL, Birrell SA, Hooper RH, Mansfield N]. Influence of carrying heavy loads on soldiers' posture, movements and gait. Ergonomics. 2006;49(14):1527-37. 